(if any), present state of the patient, and the results of the pathological tests (if any). This enables the serologist to check his work. Without this information bad work is apt to follow, irritation is caused, and no accurate interpretation of results can be given.

During the war we lost six years during which very little research work on serum tests was undertaken. Since the war we have been attempting to make this up, but the whole subject is in a state of flux and will not settle down for some years. Therefore I trust that clinicians will deal gently with venereal disease serologists, who are constantly trying to improve their reagents and technique.

\section{REFERENCES}

Price, I. N. Orpwood (1948). J. clin. Path., 1, 91. Richardson, - (1941). Lancet, $2,696$. (1940). Brit. J. vener. Dis., 16, 166.

\title{
DISCUSSION ON MODERN INTERPRETATIONS OF SERUM TESTS
}

Col. L. W. HARrison was very pleased at Dr. Price's reference to Dr. Richardson's method of preserving complement in the liquid state. As Dr. Price had said, that was a discovery which had received too little notice, and there was a danger that it might be forgotten and later be re-discovered in some other country, which would get the credit. This preserved complement was one of the useful discoveries which our dire need in the late war had stimulated. When Dr. Richardson, who was then in charge of the Ministry of Health (now the M.R.C.) Venereal Disease Reference Laboratory, had asked at the beginning of the war about the most useful lines of work for the laboratory, he (the speaker) had suggested the manufacture of reagents for serum tests, and the outcome was, inter alia, this preserved complement. At the beginning of the war he had made enquiries of the approved laboratories to discover how much need there was-for such a product, and he had been surprised at the number of laboratories which were using very indifferent complement, from undersized guinea-pigs, from guinea-pigs which had been used for tuberculosis tests of milk, of indifferent titre, etc. Most used a single pig, and few as many as three or four animals. With complement serum obtained by bleeding for the batch of tests to be done on a given day, one had to be careful to keep it refrigerated almost up to the moment of its use in the test. On the other hand, the serum preserved according to Richardson's method could, as Dr. Price had said, be left lying about at room or even higher temperatures; it could be used to the last drop in the vial, and it could be made up in batches each from a pool of not less than a hundred male guinea-pigs of not less than $600 \mathrm{~g}$. weight, each individual serum of the pool being tested for suitability before inclusion. He considered that this preserved complement serum was a most important contribution to standardization of the Wassermann test as, like the antigenic extract, it could be supplied from a central laboratory.

Dr. Price had expressed the hope-and he trusted that his hope would be realized - that with the use of complement preserved by the Richardson method one could go closer to the borderline of safety and so make the Wassermann test more sensitive. That would be valuable. He remembered that in the early days of the " 606 " era he had constantly tried to make the test as sensitive as possible so that there should be as little danger as possible of their living in a fool's paradise. The result had been what was known as " No. 1 Method, M.R.C." It used three hæmolytic doses. As far as he could remember, "No. 3 Method, M.R.C." elaborated by Fildes and McIntosh, used two doses. He himself had thought that too little, but wondered how little Dr. Price now thought could safely be used.

He saw no harm in standardization of testing so long as the people concerned were trained personally; he believed, from experience, that very few serologists could practise an author's method exactly, if they relied only on his description. As evidence of this he would cite the case of what was now known as the HarrisonWyler Method. When " No. 1 Method, M.R.C." had come through the ordeal of two international comparisons so creditably that it could confidently be recommended to the approved laboratories in this country, he had asked Dr. Wyler, who was then in charge of the Venereal Disease Reference Laboratory and had practised the method, to write a description of it in such detail that any intelligent serologist could copy it exactly. The result had been the Medical Research Council's Special Report No. 129, describing the Harrison-Wyler method, but although the description was so detailed that one could hardly imagine anyone deviating from it, of the many approved pathologists in the country who had said they practised the method, only those who had been taught it personally gave results equal to those obtained by "Dr. Wyler with identical sera.

He agreed about the standard recording of results. That was something which the League of Nations Health Organization had tried to bring about. They had recommended, and the Ministry of Health had backed the recommendation, that results should be reported as positive, doubtful, or negative. The 
Ministry had said that such a basic report could be supplemented by remarks on the strength of the test, etc., but at present reporting was on all kinds of plans, and although a clinician knew how to interpret the reports sent him from the laboratory to which he habitually sent his sera, he might be hopelessly lost among the hieroglyphics which he found on the transfer papers of a migrant patient.*

He had been interested in what Dr. Price had said about the lag in the development of the complement fixation reaction in gonococcal infections. It reminded him of the lag in the development of antibodies after prophylactic inoculation. If he remembered rightly, in the early days of anti-typhoid inoculation they had found that after the first dose it usually took ten days for the peak titre to be reached. He suggested that when one gave a dose of penicillin to a patient with gonorrhœa one slew myriads of gonococci, and the result was an inoculation with killed gonococci which might be reflected several days later in a positive gonococcal complement fixation reaction.

Dr. Price's remarks on serum relapse preceding slinical relapse took his mind back to the beginning of the " 606 " era. At that time he ran the laboratory at the Military Hospital, Rochester Row, and he persuaded the Officer Commanding to order that each patient receiving a dose of " 606 " should have his blood tested weekly. The order was not particularly well received, and he himself had become rather unpopular in some quarters because of it. Nevertheless, he thought it necessary at that time to keep a close watch on each patient from the serological point of view, particularly as they were not then giving rapidly repeated doses of " 606 " but would give one to each of a series, then two at an interval of two weeks to a second series, and so on, progressively increasing the treatment to successive serries, to discover the minimum. In such circumstances, it was important to spot the first sign of relapse, and it

* Col. Harrison wishes to add to the report of the Proceedings the following Resolution of the Second Laboratory Conference held by the Health Organization of the League of Nations at Copenhagen from May 21 to June 4, 1928, because during the discussion on Dr. from May 21 to June 4, 1928, because during the discussion on Dr.
Price's paper some speakers seemed to think that in view of the different methods practised in different laboratories a standard notation would be impracticable. The terms of the Resolution show that this fear is unjustified :

"The Conference

"Having in view the fact that serological tests for syphilis are primarily for the purpose of assisting clinicians in diagnosis, in observing progress under treatment and in tests for cure ;

"And having in view also the fact that patients frequently pass from the care of one clinician to that of another, the serum of one patient being tested from time to time in different laboratories ;

"Is of opinion that a uniform method of notation of serological results bearing approximately the same clinical interpretations would be of great value to clinicians, and proposes the following rulès :

“(1) That a negative reaction should be reportē as

(2) That a reaction which is just positive to a degree which in the hands of the serologist has been afforded practically only by sera from cases of syphilis (and of a few well-defined pathological conditions) should be reported as + or "positive'.

It is recommended in this connexion that seroIt is recommended. in this connexion that seroonly sera from cases of syphilis afford reactions which they report as " + ' or 'positive';

"(3) That a reaction which is neither negative nor positive as defined in (2) should be reported as \pm ? In making these recommendations, the Conference would
remark that there is nothing in them which would prevent the serologist adding to his report any amplifying or explanatory note which may be considered desirable (e.g., signs expressing the strength of the reaction)." seemed to him that a weekly test was the best way of doing it. He had had a lot of difficulty in persuading colleagues that a serum relapse meant failure of the original treatment and was an indication to give the patient more next time. The consequence was that a serum relapse was not always tackled promptly and it was not unusual to find later that it had preceded a clinical relapse.

DR. T. E. Osmond was interested in what Dr. Price said about complement. In the old days they used to keep a large number of guinea-pigs ; in fact they had a guinea-pig farm and bred them, and the complement titre used to vary from day to day from 1 in 40 to about 1 in 120 , so that he was always on tenterhooks until he read his results lest his complement should let him down. Now, with Dr. Richardson's complement, he had no qualms, and the titre was fairly uniform ; it did not vary by more than 5 per cent. from batch to batch and from week to week or month to month.

He found that in titration of the complement it was useful to do so not only in the straight manner but plus antigen, and also with antigen plus known negative serum. Apparently the serum protected the complement against the effect of the antigen.

As regards what Dr. Price had said about the gonococcal fixation test, it seemed to him that penicillin killed off gonococci far better and more quickly than any other method of treatment in the past. Therefore one would expect to get far fewer positive results, because there had not been time for antibody to be formed.

His third point concerned the Kahn test. Apparently Dr. Price had given up doing the Kahn test.' Dr. Osmond wondered whether Dr. Price could tell them about the preparation of Kahn antigen. He had found that batches of Kahn antigen seemed to vary. Reports from pathologists also seemed to vary during the war and he found that now and again he got a negative Kahn with a positive Wassermann, with what was obviously a strongly positive serum. This seemed to happen now much more oftert than it used to do.

He agreed with what Dr. Price had said about the desirability of full details accompanying each specimen. If clinicians sending in specimens to the pathologist would append the necessary details of diagnosis and treatment and the results of previous tests it would make the pathologist's task a much easier one and his reports much more valuable.

Dr. Hamilton Wilkie (The President), speaking of the disagreement between the Wassermann reaction and the Kahn test, said that some years ago in Glasgow they used to reckon that the Kahn test was more sensitive. They were now finding that the results of the Wassermann test were sometimes strongly positive while the Kahn test was negative.

DR. ROBERT LEES said he would advocate an absolutely standard technique, of which Dr. Price doubted the wisdom. As Col. Harrison had said, it was only when the exact technique advocated by the author was followed meticulously that consistently good results by that particular method were obtained. Therefore he urged the standard method of technique to begin with, without any fear that original minds and enterprising research workers such as Dr. Price would be stultified in their activities. There was so much disparity in the results up and down the country that it would be a step forward if they had a standard technique. It was many years since he did any serological tests, and he remembered 
with misgivings the inaccuracies they used to find when they checked up on the measurement of what they had titrated out.

He had consulted an engineer friend, who had produced a mechanical measuring device by which one could check and re-check, and he wondered whether Dr. Price had used in his work any such device to ensure the accuracy of the measurement. He thought that in addition to the new words which Dr. Price himself had introduced he would like to coin the word "serograph" for such a I new device. By means of some such method the setting out of serological results qualitatively would be of great value to the clinician, and here he had in mind not only the venereal diseases specialist but also general practitioners.

It had been mentioned that the gonococcus complement fixation test seemed to act less well nowadays. He had a strong feeling that gonorrhœa had become a much milder condition and followed a milder course, so that it could almost rank as a minor malady.

Mr. A. J. KING said that the complement fixation test for gonorrhœa did seem to be less sensitive and therefore less valuable than formerly. Dr. Price suggested that treatment with sulphonamides and penicillin might be responsible for this by modifying the normal immunity response or by producing some change in the prevailing strains of gonococci which were used to make the antigen. Before the war the test retained its value after the introduction of sulphonamides in the treatment of gonorrhœa, and was an important diagnostic measure, especially in the investigation of cases of infective arthritis of doubtful origin. The diagnostic value of this test was now relatively slight, and he thought it much more likely that the change resulted from differences in the culture media used for growing gonococci for the antigen.

Dr. Price had also mentioned that some cases of acute gonorrhœa treated early in the disease with penicillin, with apparent success, nevertheless showed a positive result to the complement fixation test for gonorrhœa in the blood serum in the course of a few weeks. The explanation that this was due to a lag in antigenic effect of killed gonococci seemed to him unconvincing. There was evidence that a proportion of patients with gonorrhœa treated with penicillin were not truly cured, and that penicillin acted in some cases as a short cut to latency. This curious finding of a delayed positive complement fixation test in apparently cured patients might be considered additional evidence in support of this view.

Dr. OrPwoon Price, in reply, said that he did not want to go into the technical details which Colonel Harrison had raised, but he would say that the amount of diagnostic complement used in the present technique was calculated in an entirely different way from what it was formerly. Relatively speaking the diagnostic dose of complement used was approximately two minimum hæmolytic doses as compared with three.

Concerning the preparation of Kahn antigen, as a result of his experience he had come to the conclusion that in the drying of the heart muscle the quantity that could be coped with was strictly limited. It was best done in a wind-tunnel at a temperature of not more than $40^{\circ} \mathrm{C}$. It was a one-man job, and not more than $2 \mathrm{~kg}$. should be dried at a time. If one attempted to deal with more, the final extract was not as sensitive as it should be. Perhaps in mass production methods these conditions of manufacture were not sufficiently appreciated.

There was no doubt that nowadays more "zone" phenomena were occurring with syphilitic sera than before the war, and this sometimes accounted for the failure of the Kahn reaction to register a positive result when one might reasonably have expected such an outcome.

One speaker asked about Richardson's modification of the Wassermann test used for the detection of false positive serum reactions. The speaker had tried this technique for over a year, and his impression was that in his hands this particular method did not give very helpful results. He had, therefore, given it up. The speaker then mentioned that the next question concerned the value of Richardson's preserved complement versus the dried complements which had been in use. Dr. Price thought the answer was that in order to use the dried complement the powder had to be mixed with distilled water, and directly this was done the resulting solution was not heat-stable and in this respect was similar to the ordinary guinea-pig serum. The great advantage of Richardson's complement was that for practical purposes it was heat-stable ; in the ice-cabinet it would keep for over a year, and even room temperature did not affect it for over three months.

With regard to the fact that in America they used Wassermann antigens at a dilution of 1 in 300 , whereas in this country the usual suspension was 1 in 15 , he would like to point out that for some time now workers in this country had been experimenting with different suspensions of Wassermann antigens. In due course the results of this work would be made known.

On the question of standard reporting, Dr. Price said he had put forward a theory, and it was only a theory, that if all results obtained by various techniques were reported in terms of the same amount of serum one should be able to do two things: (1) techniques could be compared with one another as regards sensitivity and specificity ; (2) clinicians would be able to understand blood reports no matter from whence they came.

Dr. Price's impression was that the gonococcal antigen they were now using was not as good as formerly. It was certainly more anticomplementary, and the titres of positive sera were not so high.

Dr. Price thought that it was almost impossible to be accurate in measurements of reagents used in serum testing. Apart from anything else, calculations would have to be made for varying temperatures on different days, but with the modern methods reasonable accuracy was obtained : it came well within the limits of experimental error and for the latter due allowance was made.

Mr. King had spoken of the inexplicable things that occasionally happen to tests. Fortunately these experiences were rare but they did merit, and were receiving, attention. 